
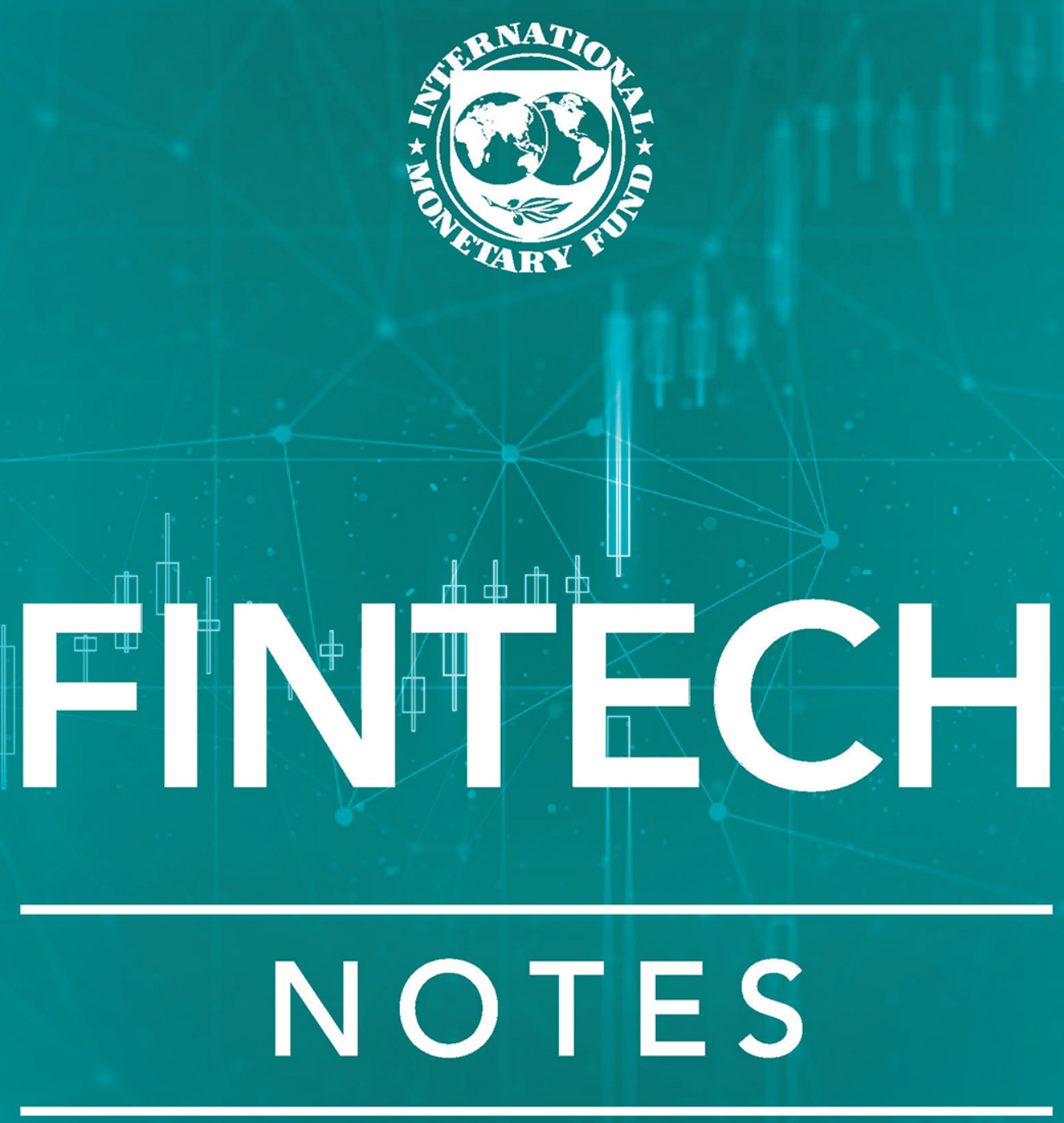

\title{
THE RISE OF DIGITAL MONEY
}

Tobias Adrian

Tommaso Mancini-Griffoli 


\section{The Rise of Digital Money}

Tobias Adrian and Tommaso Mancini-Griffoli

July 2019

$\begin{array}{lllllllllllllllllllllllll}\text { I } & N & T & E & R & N & A & T & \text { I } & \text { O } & \text { N } & \text { A } & L & \text { M } & \text { O } & \text { N } & \text { E } & T & A & R & Y & F & \text { U } & N & D\end{array}$

CInternational Monetary Fund. Not for Redistribution 


\author{
(C)2019 International Monetary Fund \\ Cover Design: IMF Creative Solutions \\ Composition: The Grauel Group
}

\title{
Cataloging-in-Publication Data IMF Library
}

\begin{abstract}
Names: Adrian, Tobias, 1971-, author. | Mancini-Griffoli, Tommaso, author. | International Monetary Fund, publisher.

Title: The rise of digital money / Tobias Adrian and Tommaso Mancini-Griffoli.

Other titles: FinTech notes (International Monetary Fund).

Description: Washington, D.C. : International Monetary Fund, 2019. | FinTech notes / International Monetary Fund. | July 2019. | Includes bibliographical references. Identifiers: ISBN 9781498324908 (paper)

Subjects: LCSH: Digital currency. | Digital currency_Law and legislation. | Banks and banking.

Classification: LCC HG1710.A37 2019
\end{abstract}

ISBN 978-1-49832-490-8 (paper)

DISCLAIMER: The views expressed in FinTech Notes are those of the author(s) and do not necessarily represent the views of the IMF, its Executive Board, or IMF management.

Publication orders may be placed online, by fax, or through the mail:

International Monetary Fund, Publication Services

P.O. Box 92780, Washington, DC 20090, U.S.A.

Tel. (202) 623-7430 Fax: (202) 623-7201

E-mail: publications@imf.org

www.imfbookstore.org

www.elibrary.imf.org 
Alipay. Libra. M-Pesa. Paxos. Stablecoins. Swish. WeChat Pay. Zelle. All, and many others, are increasingly in our wallets as consumers and on our minds as policymakers. But how should we think of these new digital forms of money? Are they money at all, and does that matter? Will they really benefit from rapid adoption? If so, what might their implications be, on the banking sector to start with — where money is customarily created and managed today? And how might central banks react? Is there an opportunity to benefit from these rapid transformations, or just a need to regulate?

This paper takes a first step in tackling these questions. Given their complexity, it limits the scope of analysis and does not venture into the normative realm. The goal of this paper is to offer a conceptual framework to categorize new digital monies, identify some of their risks, think through the implications, and offer some policy options for central banks to consider. The focus is mostly on the interplay between new forms of money and the banking sector; thus on financial stability and consumer protection. Other risks and implications - touching on financial integrity, monetary policy and capital flows, and antitrust - are mentioned in passing but do not represent the core of the discussion.

In short, the paper argues that the two most common forms of money today will face tough competition and could even be surpassed. Cash and bank deposits will battle with e-money, electronically stored monetary value denominated in, and pegged to, a common unit of account such as the euro, dollar, or renminbi, or a basket thereof. Increasingly popular

Without implicating their views, for substantial input we thank Federico Grinberg, Matthew Jones, Alfred Kammer, John Kiff, Soledad Martinez Peria, and Cedric Tille. For helpful comments we are indebted to seminar participants at Consensus 2019, the Graduate Institute in Geneva, the IMF, and the Norges Bank, as well as generous reviewers at the IMF, in particular Itai Agur, Craig Beaumont, Yan Carrière-Swallow, Giovanni Dell'Ariccia, Kelly Eckhold, Chris Erceg, Ulric Eriksson von Allmen, Vikram Haksar, Dong He, Nigel Jenkinson, Amina Lahreche, Ross Leckow and colleagues in the IMF's legal department, Aditya Narain, Adina Popescu, Tahsin Saadi Sedik, Nadine Schwarz, Herve Tourpe, and Romain Veyrun. We also thank Jeffrey Hayden and his team for superb editorial assistance. forms of e-money are stablecoins. E-money may be more convenient as a means of payment, but questions arise on the stability of its value. It is, after all, economically similar to a private investment fund guaranteeing redemptions at face value. If 10 euros go in, 10 euros must come out. The issuer must be in a position to honor this pledge.

Banks will feel pressure from e-money, but should be able to respond by offering more attractive services or similar products. Nevertheless, policymakers should be prepared for some disruption in the banking landscape. Today's new entrants in the payment arena may one day become banks themselves and offer targeted credit based on the information they have acquired. The banking model as such is thus unlikely to disappear.

Central banks will play an important role in molding this future. The rules they set will bear heavily on the adoption of new digital monies, and on the pressure these exert on commercial banks. One solution is to offer selected new e-money providers access to central bank reserves, though under strict conditions. Doing so raises risks, but it also has various advantages. Not least, central banks in some countries could partner with e-money providers to effectively provide "central bank digital currency (CBDC)," a digital version of cash. We call this arrangement "synthetic CBDC." While painting these prospects, we highlight the many questions that still need answers before concrete policies can be designed.

This paper is organized into four parts. The first reviews the different models of digital money and offers a simple conceptual framework to compare and contrast them. The second part argues that adoption of certain new models may be extremely rapid. Despite not offering the best store of value, their convenience as means of payment could be unrivaled due to network effects and online integration. In short, while the first part offers a taxonomy of change, this part concludes that some changes are here to stay. The third part discusses the potential impact of digital money adoption on the banking sector. It considers three scenarios: one in which digital monies are complements, 
one in which they are substitutes but banks are able to compete effectively for deposits, and one in which banks are transformed into private investment funds following massive deposit outflows. Other risks are also described briefly. The fourth and final part considers how central banks might respond. It discusses the potential benefits of allowing some digital money providers to hold central bank reserves and argues that this could offer an effective model to introduce CBDC to the public at large.

\section{New Digital Forms of Money}

"How much for your coffee?" 1 euro, a dollar, 10 yuan ... Whatever the price, we might pull out local notes and coins to settle the bill. Or we might swipe a card or wave our phone and walk away just as reassured that the coffee was paid for. Someone watching from another century would think it were magic. Indeed, it nearly is. The steps, hidden from view, are extraordinarily complex, involving information exchange, legal and regulatory structures, as well as back-end settlement of funds. And yet, we think nothing of it.

What if someone walked into the same coffee shop and paid using a stablecoin, or by way of a social messaging app? Or in digital tokens backed by gold or other safe and liquid assets like U.S. Treasury bills? Would we feel like the visitor from another century?

To make sense of these new payment technologies, it is useful to introduce a common vocabulary and conceptual framework. We propose one in the following section. Against this backdrop, the subsequent section briefly surveys existing and potential future means of payment.

\section{A Taxonomy—The "Money Tree"}

We compare and contrast different means of payment through the lens of a simple conceptual framework. We highlight four attributes of means of payment: type, value, backstops, and technology. ${ }^{1}$ These are discussed below and illustrated in Figure 1. Because of its branch-like structure, we refer to the figure as the "money tree," borrowing from Bech and Garratt's (2017) original use of botanical analogies in

\footnotetext{
${ }^{1}$ We do not refer to the issuer of a means of payment in this framework in order to identify criteria that capture the essence of different means of payment, without being skewed by the particular forms these take today.
}

monetary economics. (Their "money flower" is complementary to our framework; indeed, some flowers blossom on trees!)

The first attribute that defines a means of payment is type-either a claim or an object. ${ }^{2}$ The cash used to pay for the coffee mentioned earlier is an example of an object-based means of payment. The transaction is settled immediately as long as the parties deem the object to be valid. No exchange of information is necessary. The other option is to transfer a claim on value existing elsewhere. That is the case when coffee is paid for with a debit card. Swiping the card gives instructions to transfer ownership of a claim on bank assets from one person to another.

Claim-based payments simplify transactions, but require a complex infrastructure. With the advent of claim-based systems in the Renaissance, merchants could conveniently travel with letters of credit from their banks and exchange them for goods abroad instead of carrying heavy and risky gold coins in their purse. Today, most payments are claim-based. These require that payers be recognized as the rightful owners of the claim they offer, that sufficient funds be identified to back the claim, and that the transfer be registered by all relevant parties.

The second attribute of means of payment is value. When classifying claims, the relevant question is whether redemption of the claim in currency is at fixed or variable value. Fixed value claims guarantee redemption at a pre-established face value denominated in the unit of account. For payments, this useful feature allows parties to a transaction to easily agree on the value of the claim they exchange in the relevant unit of account. For instance, a claim on a bank in the form of deposits for, say, 10 euros can be exchanged for 10 euros worth of bills and notes. These claims resemble debt instruments (which may or may not pay interest) that can be redeemed upon demand at face value. Other types of claims can be exchanged for currency at variable value, meaning at the going market value of the assets that back the claim. Such claims

\footnotetext{
${ }^{2}$ The terminology used here deviates slightly from that introduced by Khan and Roberds (2009) of account- versus token-based payment systems. This is to more clearly distinguish this level of classification from the technology used, as the word "token" often denominates a blockchain-based payment instrument. Further confusion arises from a debate over whether blockchain-based technology would be better labeled as account-based since it checks ownership of coins on a ledger (see Milne 2018). For an earlier and important contribution to the discussion of money, see also Kocherlakota (1998).
} 
Figure 1. Money Trees
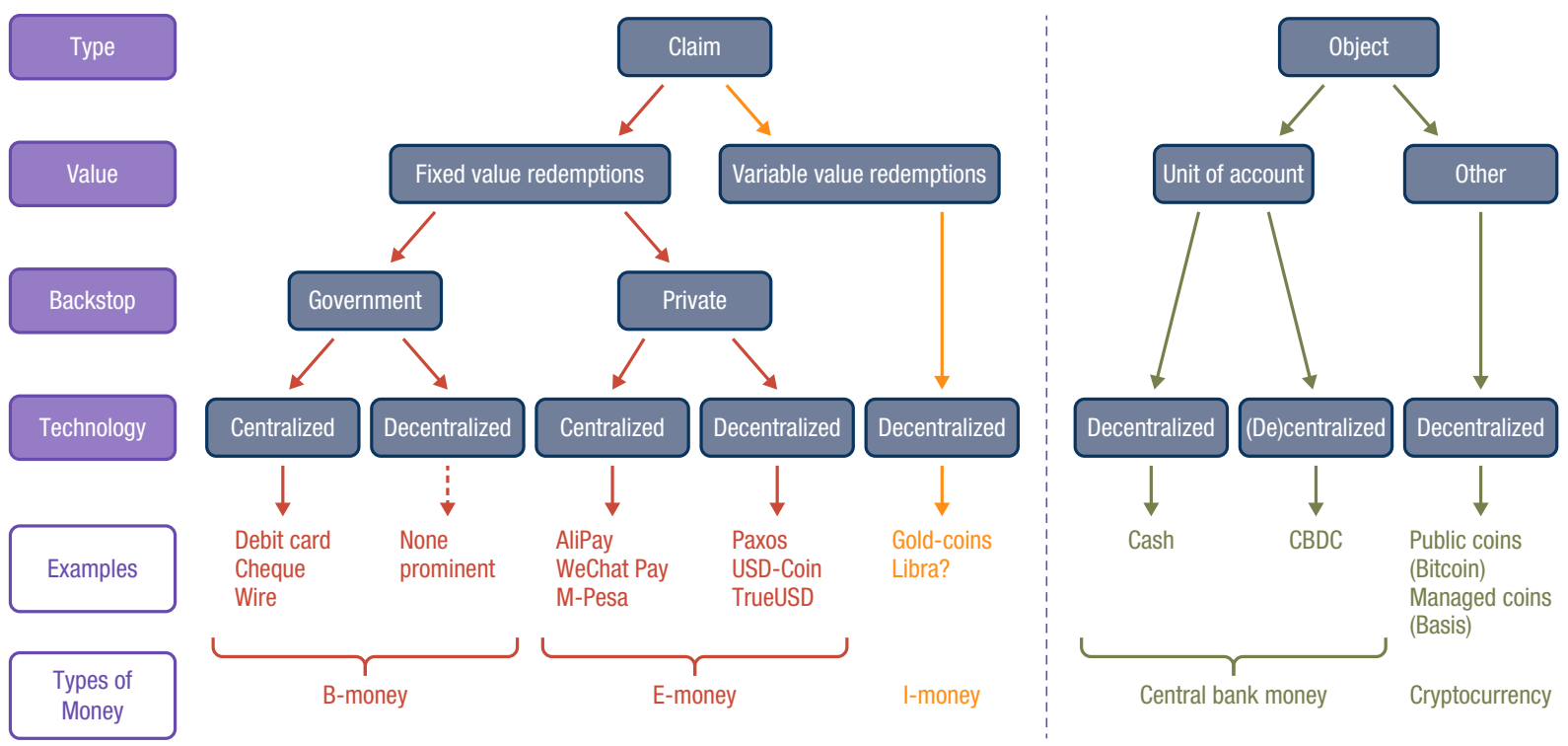

Source: IMF Staff.

Note: $\mathrm{CBDC}=$ central bank digital currency.

thus resemble equity-like instruments with an upside, but also downside risks. These parallels are intended to facilitate exposition, and do not necessarily imply that the means of payment we classify as debt-like or equity-like would be recognized as such in a court of law. When classifying object-based means of payment, the relevant question instead is their denomination, in the domestic unit of account or their own. The concept of redemption does not apply to object-based means of payment.

The third attribute of means of payments applies only to claims in fixed value. The question is whether the redemption guarantee is backstopped by the government, or relies merely on prudent business practices and legal structures put in place by the issuer. In the latter case, we call the backstop "private." The distinction is important as it may affect users' trust in the different forms of money, and the regulatory response.

The final attribute is technology; is settlement centralized or decentralized? Transactions leveraging centralized technologies go through a central proprietary server. Decentralized transactions making use of decentralized ledger technologies (DLT) or blockchain technologies are settled among several servers. These can be limited to a trusted few ("permissioned" networks), or open to the public ("permissionless"). Decentralized instruments could extend across borders more easily.

\section{Five Different Means of Payment}

The above attributes help us distinguish among five different means of payment: (1) central bank money; (2) crypto-currency; (3) b-money, which currently is issued by banks; (4) electronic money, or e-money, offered by new private sector providers; and (5) i-money, short for investment money, issued by private investment funds.

The most recognizable is central bank money in the form of cash-the notes and coins we have been carrying in our wallets for centuries. As discussed earlier, cash is an object-based means of payment. It is denominated in the local unit of account, is issued by the central bank, is settled in a decentralized fashion among transacting parties, and obviously has physical appearance. Its digital counterpart is currently being debated under the heading of "central bank digital currency," or CBDC for short. Unlike cash, CBDC would likely not be anonymous, although it could protect users' data from third parties. Its validation technology could be centralized or decentralized, and it could offer interest. Mancini-Griffoli and others (2018) offers a detailed review of CBDC designs and implications.

The other object-based means of payment is cryptocurrency. It is denominated in its own unit of account, is created (or "minted") by nonbanks, and is issued on a blockchain, commonly of the permissionless type. 
An additional distinction is relevant-whether the algorithm underlying the creation of cryptocurrency attempts to stabilize its value relative to fiat currency by issuing more currency when its price is high and withdrawing currency from circulation when its price is low. We refer to these systems as "managed coins" (some also call these "algorithmically stabilized value coins"). However, the model is not yet widely tested, though has been proposed by startups such as Basis. We refer to other cryptocurrencies as "public coins," including Bitcoin and Ethereum.

The most widespread use of claim-based money is b-money, which typically covers commercial bank deposits. In many countries, most payments entail the transfer of funds from one bank account to another, often from one bank to another, and possibly across borders. As discussed earlier, we associate b-money with debt-like instruments denominated in a unit of account, redeemable upon demand at face value. Transfers are most commonly carried out through centralized technologies, as in the case of debit cards, wire transfers, and checks.

The key distinguishing feature of b-money is that its redemption guarantee is backstopped by the government. Of course, a prudent business model helps meet potential redemption requests. But public policy also plays a role. Banks are regulated and closely supervised. Where regulation is effective, banks cannot take excessive risks and must keep ample liquidity. In addition, if banks run out of liquid assets to honor requests for withdrawals, central banks may provide liquidity via overnight loans or emergency facilities in times of systemic stress. Finally, deposits are insured in many countries up to a certain limit. To the extent this insurance is credible, consumers do not worry about their ability to redeem their deposits, and businesses should be reassured by effective regulation.

E-money is emerging as a prominent new player in the payments landscape. ${ }^{3}$ Its single most import-

\footnotetext{
${ }^{3}$ The term is also used in recent legislation. See for instance Singapore's 2019 Payment Services Act which emphasizes that "e-money" is denominated in currency, "pegged" to a currency, and is intended to serve as a "medium of exchange." https://sso.agc.gov.sg/Acts -Supp/2-2019/Published/20190220?DocDate $=20190220$. See also the European Commission's 2009 Directive on electronic money, available at https://eur-lex.europa.eu/legal-content/EN/TXT/?uri= CELEX:32009L0110. The European Commission defines e-money in a somewhat more general way, referring to "a claim on the issuer which is issued on receipt of funds for the purpose of making payment transactions." According to this definition, even pre-paid cards (which were originally associated with e-money) must be redeemable.
}

ant innovation relative to cryptocurrencies is to issue claims that can be redeemed in currency at face value upon demand (Figure 2). Borrowing from our earlier analogy, it is a debt-like instrument. It is like b-money except that redemption guarantees are not backstopped by governments. They merely rest on prudent management and legal protection of assets available for redemption. Transfers can be centralized, as in the case of many of the popular payment solutions in Asia and Africa, including Alipay and WeChat Pay in China, Paytm in India, and M-Pesa in East Africa (also called "stored value facilities"). Note that banks can also issue e-money to the extent they deal with clients that do not benefit from deposit insurance. ${ }^{4}$ Blockchain-based forms of e-money - such as Gemini, Paxos, TrueUSD, and USD Coin by Circle and Coinbase-are also popping up. These are often referred to as "fiat tokens." The term "stablecoin" is also widely used, though suffers from a vague definition which also covers the "managed coins" discussed earlier. 5

Finally, i-money is a potential new means of payment, though one which may or may not take off. ${ }^{6}$ I-money is equivalent to e-money, except for a very important feature-it offers variable value redemptions into currency; it is thus an equity-like instrument. I-money entails a claim on assets, typically a commodity such as gold or shares of a portfolio. Examples of gold-backed i-money are Digital Swiss Gold (DSG) and Novem.

${ }^{4}$ We understand this to be the case for J.P. Morgan's JPM Coin, which for now is only available to institutional clients. More information can be found on the J.P. Morgan website: https://www .jpmorgan.com/global/news/digital-coin-payments.

${ }^{5}$ Warren Weber (2019) offers a useful overview, but introduces terms that are not consistently used by others. See also PWC and Loopring (2019). Notice that the above definition of e-money does not imply that the companies listed here legally issue or create money, operate large balance sheets, or themselves have direct liabilities to their customers. Many place client funds in escrow accounts off balance sheet, as discussed later. Finally, notice also that not all the e-money providers listed above necessarily issue legally binding guarantees of redemptions at face value, despite pledging 1 for 1 convertibility into fiat currency on their websites and white papers. Models remain to be tested in stressed markets.

"Whether or not i-money is actually a form of "money" is open for debate. To economists, money is a stable store of value, a widespread means of payment, and a unit of account. No generally accepted legal definition exists, though most emphasize the ready exchange into currency, as well as denomination in a unit of account and widespread acceptance as a means of payment. Most likely, there would be a continuum of i-monies depending on the assets backing these. Those backed by the safest and most liquid assets, if widely accepted, could be considered a form of money. See He and others (2016) for a detailed discussion of what is money. 
Table 1. Summary of Forms of Digital Money and Their Attributes

\begin{tabular}{llllll}
\hline \multicolumn{1}{c}{ Elements } & \multicolumn{1}{c}{ CBDC } & Cryptocurrency & \multicolumn{1}{c}{ B-money } & \multicolumn{1}{c}{ E-money } & I-money \\
\hline Type & Object & Object & Claim & Claim & Claim \\
Value & Unit of account & Other & Fixed value redemptions & Fixed value redemptions & Variable value redemptions \\
Backstop & n/a & n/a & Government & Private & n/a \\
Technology & Centralized \& blockchain & Blockchain & Centralized \& blockchain & Centralized \& blockchain & Blockchain \\
\hline
\end{tabular}

Source: IMF staff.

Private investment funds - such as money market funds, and exchange-traded funds-offering relatively safe and liquid investments have been growing rapidly but do not yet offer widespread means of payment. In the United States in particular, the market-based financial system is larger than the traditional banking system. Private funds have begun allowing clients to make payments. However, these have relied mostly on collateralized lending (credit card payments) or rapid and low-cost redemptions into fiat currency for subsequent payments.

Today, however, shares in private investment funds could become i-money. They can be tokenized, meaning they can be represented by a coin of any amount on a digital ledger. The coin can then be traded directly, at low cost, and constitute a payment denominated in the underlying portfolio, valued at the portfolio's going worth in any currency. For instance, if B owes A 10 euros, B could transfer 10 euros worth of a money market fund to A. To the extent that the fund is liquid, its market price should be known at any point in time. And to the extent the fund comprises very safe assets, A may agree to hold these with the expectation of using these to pay for future goods and services at approximately the same exchange rate with local currency. In other words, i-money could be sufficiently stable to serve as a widespread means of payment. However, as the transfer of i-money entails a transfer of ownership of securities, it may be subject to regulatory restrictions that could limit transactions across borders, for instance.

A tangible example of i-money backed by a portfolio of assets may be Libra, the coin just announced by Facebook and members of the Libra Association. Details on Libra, announced June 18, 2019, are still to be released. However, it seems as if Libra would be backed by a portfolio (called Libra Reserves) made up of bank certificates of deposit and short-term government paper. Libra coins could be exchanged into fiat currency at any time for their share of the going value of the underlying portfolio, without any price guarantees. This sets Libra apart from e-money.
The transfer of Libra-essentially shares of Libra Reserves (though potentially without a legal claim) would comprise a payment, just as in the above example. ${ }^{7}$

We offer Table 1 as a summary of the different forms of money we just evaluated along the four elements of our conceptual framework.

\section{Adoption of E-money Could Be Rapid}

If a means of payment-either claim or object-has stable value in the unit of account most relevant to users, it is much more likely to be widely adopted. For one, parties will agree to hold it at least for the time it takes to complete the transaction. In addition, they will more easily agree on its value relative to the contracted transaction price, usually expressed in a common unit of account. Stable value is thus a necessary condition for an object or claim to be widely used as a means of payment. The question is how stable? And can e-money be as stable as some of its competing forms of money? If not, can its advantages as a convenient means of payment compensate and still lead to widespread adoption? Note that we focus here on e-money, but many of the insights could extend to i-money if and when it also takes off.

\section{How Stable is E-money?}

Differences in terms of stability of value are actually quite marked between different forms of money. Users may compare monies according to returns and risks. We measure these in nominal terms, relative to domestic currency, unless otherwise noted. ${ }^{8}$ This helps us focus just on the design of monies, not on their macroeconomic context, which would be common to all designs.

${ }^{7}$ We do not advance a definite view as to whether Libra should be considered a security from a regulatory standpoint.

${ }^{8}$ Our decision to focus on the nominal stability of value relative to the domestic currency is less defendable in countries with very high inflation in which the means of payment denominated in foreign currency may be preferred independently of other design features. 
Figure 2. Stylized e-money Setup

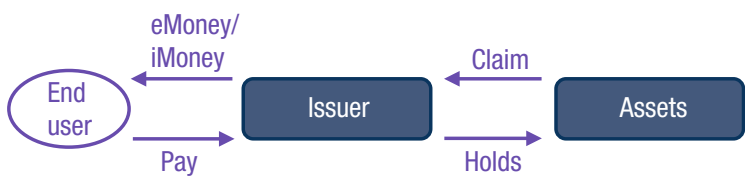

Source: IMF staff.

Cryptocurrency is by far the riskier, though it potentially offers higher returns (capital gains). This is especially true of public coins whose value in fiat currency can fluctuate significantly. The standard deviation of day-on-day changes in Bitcoin prices is approximately 10 times higher than in most G7 currency pairs, and even a little higher than in the Venezuelan Bolivar to U.S. dollar exchange rate.

Managed coins exhibit lower price volatility by design. However, these use some variation of a simple system to stabilize value, which is not always credible. Issuers purchase coins when their value is low using another asset, and they sell coins when their value is high. While public coins are akin to a floating exchange rate, managed coins resemble managed exchange rates. Their outstanding stock is supposed to keep the exchange rate with fiat currency within tight bands. However, we know too well the common fate of pegs. When a country's economic fundamentals are off-kilter, the central bank can run out of the foreign exchange reserves needed to purchase domestic currency in the marketplace. Providers of managed coins can also run out of assets to support the price of their coins, especially because they may stand on shaky fundamentals — use determining value, and value encouraging use. Nevertheless, never say never when it comes to technological innovation!

At the other extreme, central bank money-cash or CBDC_-is perfectly stable as a store of value (again, in nominal terms). Central bank money cannot be redeemed at the central bank against anything (such as gold), as it is the unit of account. Of course, technically, government bonds balance central banks' cash liabilities to the public in a modern fiat system. As a consequence, the government's solvency underpins the value of money-but in real terms. Unfortunately, there are plenty of examples of countries with weak fiscal positions whose currency is wiped out through hyperinflation due to a run to foreign currency or monetary financing of the debt.
Then come the monies in the form of claims which are potentially much riskier by design. Equity-like instruments like i-money directly inherit the risk of their underlying assets. I-money backed by Treasury bills will be less risky than i-money backed by stock market shares.

Backing in liquid and safe assets also helps b-money, but it is especially the government backstops that provide safety as a store of value, as discussed earlier; the bank deposits and central bank liquidity.

What about e-money? Stability of value comes from the guaranteed redemption at face value. But because e-money does not benefit from government backstops as does b-money, can it always be in a position to honor redemption requests? It must privately generate the means to do so through a strong balance sheet and specific legal structures. Otherwise, e-money may be subject to run-risk. In essence, e-money shares many characteristics of constant net asset value (CNAV) funds, which also pledge that customers will at least get their money back. ${ }^{9}$ But as we were reminded after the Lehman bankruptcy, runs materialized when money market funds "broke the buck." That is, investors believed these funds would return a dollar for each dollar invested, but they got back less when the value of the funds' riskier assets plunged as markets crashed.

In general, e-money is exposed to four types of risks, in addition to operational risk (including cyber risk), which is common to all means of payment to different degrees. Liquidity, default, market, and foreign exchange rate risk all potentially undermine the guarantee of redeemability at face value.

- Liquidity risk means there may be a lag before redemption requests can be met. Liquidity risk depends on the market liquidity of the assets held by the e-money issuer.

- Default risk captures the scenario in which the e-money issuer defaults, leaving client funds at risk

${ }^{9}$ The parallel is made for expositional purposes. Differences remain. For instance, CNAV funds typically do not have the legal obligation to cap investors' losses, despite striving to do so. 
THE RISE OF DIGITAL MONEY

Figure 3. E-money with Trust to Protect Client Funds

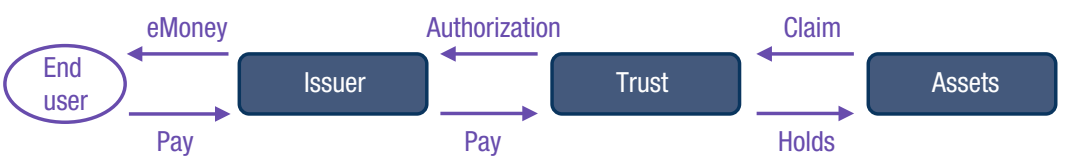

Source: IMF staff.

of seizure by other creditors. Default can occur due to losses on other business activities or the inability to meet one's debt obligations.

- Market risk emerges from the assets held by the e-money provider. Sufficiently large losses relative to the capital of the e-money provider can put redemptions at risk.

- Foreign exchange rate risk is present to the extent that claims held as e-money are denominated in a currency other than the domestic unit of account. That is the case of Libra, for instance which is denominated in a basket of currencies.

To minimize exposure to these risks and thus maximize the stability of their value in currency, e-money issuers have various options. Extending the earlier exchange rate analogy, these amount to pushing e-money to resemble a currency board, and embracing transparency.

- They can invest in safe and liquid assets, such as short-term government paper. The safest and most liquid assets of course are central bank reserves. These can be held directly, if access is granted, or indirectly through a specialized bank such as a payments bank in the United States or India or a special purpose vehicle with a bank license.

- They must contain the creation of e-money so that it is always lower or equal to the value of the client funds received. Over-issuance would undermine the ability to meet redemption requests.

- Assets held must not be encumbered-namely, pledged as collateral for loans - and would ideally be segregated from the e-money issuer's balance sheet in order to protect client funds in the case of bankruptcy.

- Sufficient capital would help offset losses and thus ensure full redemption of client funds. Although this is not a paper on regulation, clearly regulation of e-money issuers must be quickly strengthened where necessary in order to protect customers and avoid risks to financial stability. ${ }^{10}$

E-money issuers are adopting some of the above options. To date, the most popular assets held by e-money providers are bank deposits. These have the advantage of offering redemption on demand at face value, but banks can default. And because e-money issuers are wholesale creditors, their funds are generally not protected by deposit insurance. Other systems will have to be developed to protect e-money providers and their clients from bank defaults, perhaps along the lines of private investment protection plans.

To minimize risk that e-money providers default, client funds may be transferred to trusts (illustrated in Figure 3). ${ }^{11}$ Trusts have the advantage of segregating client funds from the balance sheets of e-money providers. However, the legal protection of trusts is not watertight in all jurisdictions. As a result, it may not always be possible to protect client funds from other creditors in courts of law. If anything, legal proceedings could delay the re-appropriation of funds. Depending on the country, other legal structures may be more effective in protecting client funds.

\section{E-money Adoption Could Be Fast for Its Attractiveness as a Means of Payment}

So if e-money cannot be as stable a store of value as b-money or central bank money, could its adoption still take off? The answer is yes, due to its relative

\footnotetext{
${ }^{10}$ If e-money were to become its own unit of account through very widespread use, these risks would become less relevant, as users may no longer seek redemption unless e-money were debased through excessive issuance (in the same fashion that households and firms sell domestic currency for foreign currency). In this case, the new form of money would become akin to a fiat currency, and its issuer to a central bank. Chances of this scenario occurring are higher if the particular form of e-money were required for purchases, such as on a popular retail shopping site. This is akin to the government "generating demand" for domestic currency by requiring that taxes be paid in it.

${ }^{11}$ Taken from Duffie (2019).
} 
attractiveness as a means of payment. Clearly, this will depend on country circumstances and the technological advancements adopted by banks to improve the convenience of b-money. We will come back to this point when discussing the impact of e-money growth on banks. But even where b-money can be exchanged very efficiently, e-money can bring additional benefits as noted below.

In China and Kenya, for instance, the question is moot; e-money already rules. Ninety percent of Kenyans over age 14 pay with M-Pesa, and the value of e-money transactions in China, such as with WeChat Pay and Alipay, surpass those worldwide of Visa and Mastercard combined.

The adoption of e-money may also grow rapidly elsewhere for one or several of at least six reasons:

- Convenience: E-money is better integrated into our digital lives relative to b-money or central bank money. It is typically issued by companies that fundamentally understand user-centered design and integration with social media.

- Ubiquity: Cross-border transfers of e-money would be faster and cheaper than of cash and bank deposits. However, various other hurdles might emerge, such as requiring that market makers in foreign countries be ready to provide redemption in local currency. To limit the scope of this paper, we do not explore further the rich and important topic of cross-border payments using digital currencies.

- Complementarity: If assets like stocks and bonds were moved to blockchains, blockchain-based forms of e-money would allow seamless payment of automated transactions (so-called delivery versus payment, assuming blockchains were designed to be interoperable), thereby potentially realizing substantial efficiency gains from avoiding manual back-office tasks. More generally, e-money functionality more naturally lends itself to being extended by an active developer community, which may draw on open source codes as opposed to proprietary technologies underpinning b-money. Developers could for instance allow users to determine the goods that e-money could purchase-a useful feature for remittances or philanthropic donations.

- Transaction costs: Transfers in e-money are nearly costless and immediate, and thus are often more attractive than card payments or bank-to-bank transfers especially across borders. As a result, people might even agree to sell their car for an e-money payment as the funds would immediately show up in their account, without any settlement lag and corresponding risks.

- Trust: In some countries where e-money is taking off, users trust telecommunications and social media companies more than banks. ${ }^{12}$

- Network effects: If merchants and peers also use e-money, its value to prospective users is all the greater. And as new users join, the value to all participants—existing and prospective—grows.

The first five reasons may be the spark that lights the fire of e-money; the sixth is the wind that could spread the blaze. The power of network effects to spread the adoption of new services should not be underestimated. Why did we switch from email to text messaging, and from text to social messaging platforms like WhatsApp in such short periods of time? The adoption of WhatsApp was one-third faster than that of Gmail. And today, WhatsApp has surpassed Gmail in user-base and is well past the 1.5 billion users mark. The dominance of WhatsApp relative to standard text-messaging solutions is even more stark. ${ }^{13}$ At the beginning, however, all allowed communication in writing. Why did one form come to dominate? It was a tad easier on the social messaging apps, a tad more integrated with other features such as photos, a tad friendlier, cheaper . . But, importantly, it was interoperable across providers, phones, and countries, and all our friends used it. We could even invite them to group chats. Network effects amplified the small objective differences in features. WhatsApp in particular is a great example of a service that spread without any marketing, only through word of mouth—only through network effects.

Economists beware! Payments are not just the act of extinguishing a debt. They are an exchange, an interaction between people - a fundamentally social experience. If two people use the same payment method, a third is more likely to join. And, yes, payments can be fun, more fun, at least, in e-money and i-money than in paper bills. Emojis, messages, and photos, or perhaps a customer rating, cannot be sent with a mere debit card payment!

\footnotetext{
${ }^{12}$ See for instance Cuthell (2019) and Sapienza and Zingales (2012).

${ }^{13} \mathrm{~A}$ thorough discussion of WhatsApp's and Gmail's growth is provided on their respective Wikipedia pages: https://en.wikipedia.org/ wiki/WhatsApp\#User_statistics and https://en.wikipedia.org/wiki/ Gmail\#History_2, and further discussion is available online such as on https://growthhackers.com/growth-studies/whatsapp.
} 
This is where the world's big tech companies and fintech start-ups come in. They are experts at delivering convenient, attractive, low-cost, and trusted services to a large network of customers. User-centered design is second nature. They understand how people behave on social media and online. They can make payments integrate seamlessly. They did it once with social media; they could do it again with money, whether with an " $e$ " or even perhaps an "i" in front of it.

\section{Effects of E-money on the Banking Sector}

If e-monies took off because of their attractiveness as means of payment, backed by large big tech firms with large existing user bases_-or nimble fintech start-ups-will that spell the demise of b-money and the banks behind them? Will retail bank deposits migrate to e-money providers in large amounts? Not so fast. In fact, banks are unlikely to disappear. This part considers three possible scenarios. First, however, it lays out other risks of rapid e-money adoption for completion, though without going into details to limit this paper's scope.

\section{Risks of Rapid E-money Adoption}

Risks other than banking disintermediation are also possible and need to be understood and carefully weighed. Regulatory frameworks generally exist to tackle many of these risks, but likely need to be revised and strengthened. For instance, financial services offered by big tech firms might be designated and regulated as being globally systemic. One guiding principle is that regulation should be proportionate with the risks and types of services offered. Fintech firms that offer banking services would be regulated as banks, and firms that offer the equivalent of investment funds, or broker dealer services, would be regulated as such.

Earlier, we touched on risks to consumer protection and financial stability stemming from runs on e-money which have features of CNAV funds. In addition, risks may emerge to privacy, monetary policy transmission, seignorage following a drop in currency demand, market contestability, financial integrity, as well as policymaking in general if precious data such as on cross-border capital flows were lost.

Risks to market contestability — namely the emergence of large monopolies that hamper entry of new firms and extract rents-may be difficult to contend with. E-money providers may be natural monopolies due to the strong network effects spurring their adoption (though eventually leading to monopoly power and favoring first movers), the large fixed costs needed to establish operations at scale, and the exponential benefits of access to data. Indeed, very large datasets allow inference of client behavior based on near-randomized trials controlling for a rich set of characteristics, as well as those of peers identified through transactions. In addition, firms may be able to extend their monopoly position to related services which can also leverage the same dataset.

Risks to monetary policy transmission, for instance, could emerge from currency substitution in countries with weak institutions and high inflation if new forms of money become widespread. As usage of foreign e-money spreads, the domestic unit of account could switch to that in which e-money is denominated. For instance, instead of redeeming e-dollars coming into the country from remittances into domestic currency, both merchants and households might be happy holding e-dollars. Soon enough, merchants would start pricing their goods in dollars. As a result, central banks could lose monetary policy control. ${ }^{14}$

Relative to financial integrity, decentralized technologies in particular raises new challenges. Issuers of blockchain-based money and their partners involved in onboarding clients and verifying transactions will remain liable for anti-money-laundering and counter-terrorism financing (AML/CFT) obligations. These include identifying customers, monitoring transactions, and reporting suspicious transactions to the competent authorities, as well as respecting United Nations or country-specific sanctions lists. However, when transaction verification is decentralized, and the number of entities involved (such as crypto-exchanges, governance bodies, wallet providers, client fund managers, and market makers) very large and fragmented across firms, sectors and countries, enforcement of AML/CFT obligations becomes difficult. If anything, international cooperation will become all the more relevant to avoid regulatory arbitrage and a dilution of regulation.

\section{Scenario 1: Coexistence}

Returning to disintermediation risks, the first, and most likely, scenario is that e-money and b-money will coexist; the battle will wage on. To begin with, banks are often in a position of strength. They have captive

\footnotetext{
${ }^{14} \mathrm{~A}$ recent speech (May 2019) by Tobias Adrian touches in these important issues. See also Edwards and Magendzo (2001).
} 


\section{Figure 4. Stylized Example of Deposit Substitution}

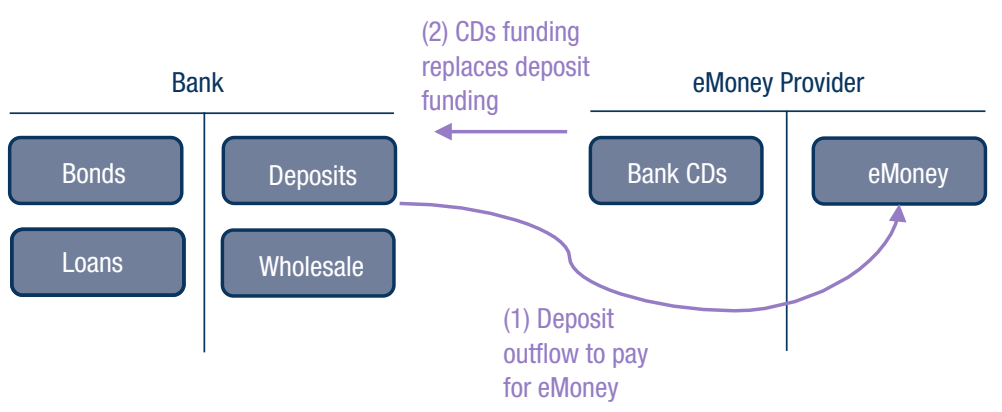

Source: IMF staff.

Note: $C D=$ certificate of deposit.

users - though potentially much smaller user bases than large big tech firms — and strong distribution networks. They can cross-sell other financial services to customers, including means to overcome cash-in-advance constraints by offering overdraft protection or credit lines.

Moreover, e-money providers might recycle many of their client funds back to banks, as certificates of deposit or other forms of short-term funding (Figure 4). Clearly, from the banks' standpoint, the outcome is not optimal. First, they would swap cheap and stable retail funding for expensive and runnable wholesale funding. Second, they could be cut off from client relationships, and third they could lose access to valuable data on customer transactions. In addition, funding from e-money providers might be concentrated in a few large banks (though it would eventually trickle down to other banks). So smaller banks might feel greater funding strains, or at least experience greater volatility in funding.

In any case, banks can respond in three ways: offer higher interest, improve services to retain deposits (including by buying up promising startups), or find other sources of funding.

Banks have leeway to raise interest on deposits. Since banks make profits from maturity transformation (holding assets of longer term than deposit liabilities), they may be able to offer higher interest than e-money providers, even than conservative i-money providers (note, Libra has announced that it will not offer any interest to users). E-money providers must hold very liquid assets and thus could offer approximately overnight money market rates. Higher rates on deposits could be met with greater operational efficiency, lower profits, and potentially slightly higher lending rates. Andolfatto (2018) argues that if banks start from a position of market power, there is leeway to increase rates on deposits without significant macroeconomic consequences. Drechsler, Savov, and Schnabl (2018) point to banks' market power as a prime explanation for the low and stable rates they tend to pay on deposits across countries. However, banks must cover distinct costs such as deposit insurance fees, regulatory costs, and branch networks.

Banks could also rival the quality of payment services in e-money, at least domestically, though not necessarily across borders. In fact, b-money has grown increasingly convenient thanks to payment innovations such as touchless cards and phone-based apps that facilitate payments by debit card — such as Venmo, Zelle, or Apple Pay Cash in the United States. More fundamental change is also possible through "fast payment" systems rolled out by central banks in many countries (as TIPS_-TARGET instant payment settlement - in the euro area) allowing banks to settle retail transactions nearly in real time at negligible cost. A related example, though developed by a consortium of banks, is Swish in Sweden. Even JPM Coin is a prominent example of how banks are fighting back by entering the e-money space.

But will banks adapt fast enough? Can they live and breathe online customer satisfaction, user-centered design, and integration with social media the way big techs do? Are they sufficiently agile to change business models? Some will be left behind no doubt. Others will evolve, but must do so quickly.

In the transition, central banks can help. They can provide temporary liquidity if banks lose deposits rapidly. But central banks will be reluctant to offer this crutch for too long as their balance sheets might grow, and they could become embroiled in difficult lending decisions. Short of this, banks can also find 
THE RISE OF DIGITAL MONEY

\section{Figure 5. Stylized Example of Splitting the Payment and Credit Functions of Banks}

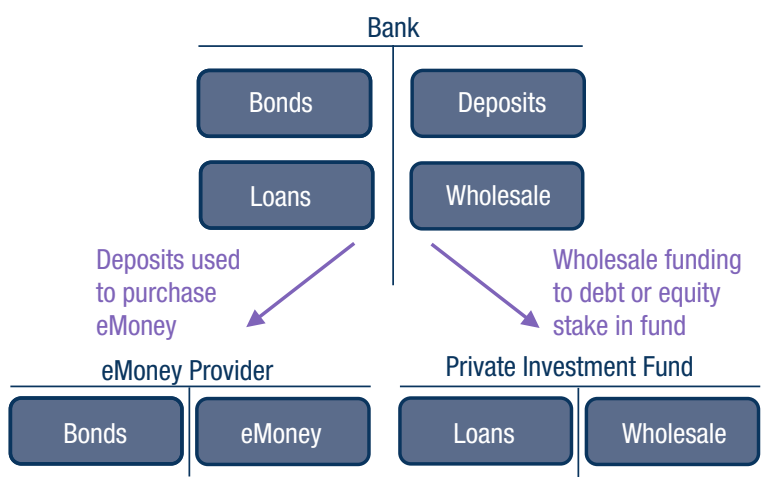

Source: IMF staff.

alternative forms of funding by issuing longer-term debt or equity.

\section{Scenario 2: Complementarity}

In the second scenario, e-money providers could complement commercial banks. This outcome is already visible in some low-income and emerging market economies. E-money can draw poorer households and small businesses into the formal economy, familiarize them with new technologies, and encourage them to migrate from making payments to seeking credit, more complex saving instruments, accounting services, and financial advice provided by commercial banks. In Kenya, for example, credit growth increased steadily for several years as e-money was being rapidly adopted after 2008 .

But even in advanced economies, a partnership could be envisioned. E-money providers could leverage their data to estimate customers' creditworthiness, and sell their findings to banks or intermediate bank funding for a more efficient allocation of credit. Moreover, it is perfectly possible that some of the larger e-money providers will eventually migrate to the banking business, bolstered by the data they have accumulated and their scale, and attracted by the margins from maturity transformation. Thus, while today's brands could disappear, the banking model is unlikely to be forgotten.

\section{Scenario 3: Takeover}

The third scenario entertains a radical transformation of the banking model whereby banks mostly rely on wholesale funding, and credit is increasingly inter- mediated by markets. While we view this as the least likely scenario, it is a contingency worth considering to better prepare for, and attempt to shape, the future.

Commercial banks' deposit-taking and credit functions could be split. The deposits we hold for payment purposes could migrate to e-money, and in turn could be held abroad, in government bonds, or in central bank money. And those we hold as savings could be channeled to mutual funds, hedge funds, and capital markets for the allocation of credit. Alternatively, they could remain in banks, which would themselves mostly rely on wholesale funding.

The result would be a very different world and a very different banking model (Figure 5). It would greatly limit fractional banking. Fractional banks take deposits but only hold a fraction of these in liquid assets such as central bank reserves and government bonds; the rest is lent to households and firms and thus helps the economy grow.

Would it be a desirable world? It depends on whether we believe fractional banks are an accident of history or a socially efficient solution, and whether technological innovation changes their relative efficiency.

Unfortunately, feelings are strong in this area, but empirics are scarce. ${ }^{15}$ How much liquidity would get locked up in e-money and no longer be available to extend loans to the private sector? Currently, banks are able to lend the liquidity buffers we hold for a rainy day - to cover liquidity shocks such as dental work or car repairs_-assuming we will not all get hit by the

${ }^{15}$ Seminal papers in this field are Calomiris and Khan (1991), Diamond and Rajan (2001), and Kashyap, Rajan, and Stein (2002). 
same shock at once. Would only these buffers migrate to e-money, or would more? What about uninsured deposits? Could monetary policy offset the effect? Would credit to firms and households be rationed or become more expensive as mutual and hedge funds are required to receive funding before they can extend a loan? But don't banks have to abide by the same prudent rules in practice, despite being able to create loans and deposits at the same time on paper? Would specialized funds develop to offer and hold nonstandard and illiquid loans such as mortgages? Would these be able to lock in funding for long enough to support credit even during stressed times? What portion of these loans could be securitized and mutualized? And could the monitoring function that banks offer be taken up by funds, by specialized agencies with some skin in the game, or simply by technology such as artificial intelligence and big data analytics? And what about the shadow banking sector, which we generally believe is risky and under-regulated? Would funds flow from the shadows to e-money providers, and might this enhance welfare? ${ }^{16}$ Whatever the answers to these questions, the transition could be rocky.

It is urgent that we seek answers to these questions. With those in hand, we will be able to better assess the costs and risks of a world with more e-money. And only then will we be able to plan a course for policy, leaning in favor or against this new world, which is already emerging before our eyes.

\section{The Role of Central Banks and Synthetic CBDC}

What will we use in the future as a means of payment and store of value: e-money, or potentially even i-money, issued by big tech firms, or commercial bank deposits? Will e-money encroach on the fractional banks we know today? Policymakers will not be able to remain bystanders. Central banks in particular could play a key role in shaping this future.

\section{Today's World}

To date, central banks have favored fractional banks. As discussed earlier, central banks and other regulators help ensure the safety of our deposits by supervising banks and offering liquidity when needed.

\footnotetext{
${ }^{16}$ Such is the argument in Greenwood, Hanson, and Stein (2016).
}

Importantly, central banks also settle payments between banks. Otherwise, interbank payments would be expensive, slow, and potentially contentious. Indeed, short of exchanging cash or gold, banks have to extend credit to each other in order to settle payments between themselves and their customers.

This is where the central bank comes in. All banks hold accounts at the central bank, and a payment from one to the other is settled by transferring perfectly safe funds (called central bank reserves) from one account to another. Not only does this remove credit risk from inter-bank transactions, it also ensures that payments are interoperable across banks. As a result, no single bankhowever large its network- has an advantage in allowing payments among more customers. Interoperability is essential to level the playing field between banks.

\section{Tomorrow's World: What If E-money Providers Could Hold Central Bank Reserves?}

What if providing a level playing field also meant offering settlement services to e-money providers? What if these firms could also hold central bank reserves, just like large banks, to the extent that they satisfied certain criteria and agreed to be supervised?

The suggestion is not new. In fact, some central banks, such as the Reserve Bank of India, the Hong Kong Monetary Authority, and the Swiss National Bank already offer special purpose licenses that allow nonbank fintech firms to hold reserve balances, subject to an approval process. The Bank of England is discussing such prospects. Meanwhile, China has gone even further. The central bank requires the country's large payment providers, Alipay and WeChat Pay, to hold client funds at the central bank in the form of reserves. Despite these examples, many of the details of the proposal to allow e-money providers to access central bank reserves would have to be worked out.

The ability to hold central bank reserves would fill the sails of e-money providers by allowing them to overcome market and liquidity risk, and would transform these into narrow banks. Narrow-as opposed to fractional-banks are financial institutions that cover 100 percent of their liabilities with central bank reserves and do not lend to the private sector. They merely facilitate payments. ${ }^{17}$

\footnotetext{
${ }^{17} \mathrm{~A}$ seminal paper is Tobin (1987).
} 
Fractional banks would feel greater pressure. For one, they would no longer benefit from wholesale funding from e-money providers, as discussed earlier. Nevertheless, banks should still be able to fight back with more attractive service offerings (scenario 1 discussed earlier) and some e-money providers could persist in funding banks to seek higher returns (if given the option), or could evolve into banks themselves (scenario 2 discussed earlier).

While banks should be able to hold their ground in normal times, a question mark arises in crisis times. Would there be massive runs from bank deposits into e-money in times of crises? If client funds backing e-money were held as wholesale funding for banks, the run could be in reverse, from e-money to b-money as clients seek the protection of banks' deposit insurance. But if client funds were held as reserves at the central bank, then run risks cannot be discounted. Certainly, uninsured deposits might migrate from banks to e-money providers.

However, several points attenuate this apparent threat. First, in many countries, systemic bank runs are associated with runs to foreign currencies and would thus occur irrespective of e-money. Second, there are already safe and liquid assets in many countries, such as Treasury-only funds, but they did not see massive inflows during the global financial crisis. Third, while bank runs can be destabilizing, they can be countered by central bank lending as long as the effects are temporary. In this case, lending to banks would balance inflows to central bank reserves. In any case, the risk of rapid disintermediation of the banking sector should be taken seriously.

\section{Potential Advantages}

There are also important benefits to consider from offering e-money providers access to central bank reserves, or potentially requiring e-money providers to do so.

The first is ensuring the stability of e-money. As argued earlier, trust in e-money can be shaken by default, market, liquidity and FX risk, as well as potential over-issuance relative to backing in client funds. All can lead to costly runs and devaluations, undermine confidence in the payments system, destroy significant wealth, and ultimately put financial stability at risk.

E-money backed by central bank reserves can eliminate liquidity and market risk, and thus attenuate default risk. It would also facilitate oversight of issuance related to the scenario of client funds being dispersed across many banks. Assuming the elimination of default risk through appropriate legal structures and potential regulatory reforms, e-money would then be credibly redeemable at par for domestic currency.

Second, central banks could ensure interoperability of payments and thus protect consumers from the growth of e-money monopolies offering payments among a large network of users. A payment from one to another in e-money must be shadowed by a shift of funds from one e-money provider's trust account to another's. Only then would the newly held e-money be fully backed and redeemable. Such contemporaneous transfers of client funds would be seamless if carried out on the central bank's books. In addition, central banks could require e-money providers with access to their accounts to adopt technological standards allowing e-money wallets to "talk to each other," enhancing interoperability and competition.

Third, central banks and regulators might not be able to contain the growth of large e-money monopolies. These could be large international firms operating as nearly natural monopolies given the importance of network effects, rents from access to data, and the sunk costs required for entry. In that case, central banks might want to give preference to domestic e-money providers operating under their direct supervision by offering them the means to issue money that is perfectly safe and liquid, and thus potentially more attractive than the foreign offering. This would also allow central banks to retain seignorage revenue, to the extent they did not pay interest on reserves held by e-money providers. ${ }^{18}$

Fourth, monetary policy transmission could be more effective for two reasons. The first follows from the above point. By offering an attractive means of payment in domestic currency, substitution into foreign currency ("dollarization") provided by global e-money providers is less likely. Second, central banks could pay interest on the reserves held by e-money providers. Doing so would more directly transmit monetary policy rates to consumers and-as argued earlier-put greater pressure on banks to offer rates on deposits

\footnotetext{
${ }^{18}$ If they did pay interest on reserves, and if competition in the e-money space forced providers to transfer this interest income to e-money holders, then seignorage can be thought of as being rebated to the population. Seignorage here is defined as the profits made by the central bank by issuing liabilities at a rate lower than that received on assets.
} 
Figure 6. Stylized CBDC Setup

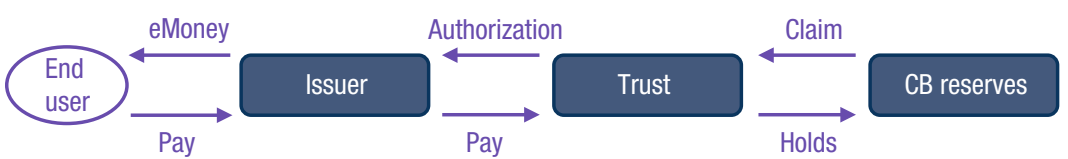

Source: IMF staff.

Note: $\mathrm{CB}=$ central bank.

closer to the policy rate to avoid losing customers. ${ }^{19}$ Interest on e-money could even be brought into negative territory. If anything, this would alleviate the constraint of the effective lower bound. On the contrary, zero-yielding e-money would allow households and firms to rather easily circumvent negative rates on bank deposits.

Finally, central banks could establish clear conditions to grant licenses to e-money providers, including strict supervision and oversight by the central bank or other authority. For instance, selected providers would be responsible for appropriate customer screening, transaction monitoring and reporting in accordance with know-your-customer and anti-money-laundering regulation, as well as security of wallets and customer data. Control over who can receive and hold e-money may also prove helpful to limit its spread beyond a country's borders, for instance.

Note that several of the advantages above from offering e-money providers access to central bank reserves could be achieved through other means. However, many remain incomplete and potentially less effective. For instance, e-money providers would remain in the less regulated shadow-banking realm. Countries may find it difficult to impose appropriate regulation such as requiring disclosure of risks to clients, and sufficient capital and liquidity buffers. As we found out with CNAV funds following the Lehman bankruptcy, even the full disclosure of risks may not be well understood by clients. Another example is that client funds placed in custodian accounts or bank deposits might not be immediately transferred following the sale of e-money from one provider to another, thus limiting interoperability.

\footnotetext{
${ }^{19}$ The interest paid to e-money providers could differ from the interest paid to commercial banks on reserves, and the wedge between the two rates could be a policy variable in and of itself.
}

\section{Synthetic Central Bank Digital Currency}

Allowing e-money providers to hold central bank reserves would be a major policy decision with various advantages and risks and potentially far-reaching consequences, such as spurring innovation, enabling the trading of blockchain-based assets, and facilitating cross-border payments, a topic taken up in Adrian (2019).

A more immediate consequence stands out: The creation of central bank digital currency! After all, if e-money providers can hold and transact in central bank reserves, if these are protected against other creditors when the e-money provider goes bankrupt, and if e-money is issued one for one for reserves, then e-money holders too can essentially hold and make transactions in a central bank liability (Figure 6). Bingo! That is the essence of CBDC.

But this version of CBDC is not the full-fledged type discussed at length by policymakers. In that version, central banks are the major CBDC operators, responsible for many of the following steps: performing customer due diligence, offering or vetting wallets, developing or selecting the underlying technology, offering a settlement platform, managing customer data, monitoring transactions, and interacting with customer requests, complaints, and questions. Each of these raises risks of glitches and cyberattacks, entails significant costs, and puts the central bank's reputation at risk.

We suggest a different approach, one established in a public-private partnership, which we call "synthetic CBDC," or simply "sCBDC." ${ }^{20}$ After all, the central bank would merely offer settlement services to e-money providers, including access to central bank reserves. All other functions would be the responsibility of private e-money providers under regulation as discussed above. This of course assumes that the

\footnotetext{
${ }^{20}$ The term "synthetic" does not imply that the underlying assets - in this case reserves - are not needed, but that CBDC as a form of money can be recreated using different building blocks.
} 
public understands the limited responsibility of the central bank and does not see sCBDC as an entirely central-bank-branded product. Reputational risk for the central bank would otherwise come back to the fore. However, as is true for commercial banks today, fraud or technical glitches related to a person's debit card, for instance, are not blamed on the central bank, even though commercial banks have access to reserves.

sCBDC is thus a far cheaper and less risky model of CBDC for central banks, relative to the full-fledged model. It is also one that preserves the comparative advantage of the private sector to innovate and interact with customers, and of the central bank to provide trust and efficiency.

Is this good or bad? It depends first on whether countries see advantages in CBDC. If so, we argue,
sCBDC may be a more effective way to proceed. But discussing the pros and cons of CBDC lies outside the scope of this paper. Mancini-Griffoli and others (2018) delves into relevant considerations. These include financial inclusion and cost efficiency, as well as the safety of the payments system and consumer protection if cash disappears and settlement services are increasingly provided by large private sector players.

Will sCBDC be the central bank money of the future? Will it rival b-money and potentially i-money? Much lies in the hands of central bankers, regulators, and entrepreneurs, and much remains to be seen. But one thing is certain: Innovation and change are likely to transform the landscape of banking and money as we know it. 


\section{References}

Adrian, Tobias. 2019. "Stablecoins, Central Bank Digital Currencies, and Cross-Border Payments: A New Look at the International Monetary System," speech given at the IMF-Swiss National Bank Conference, Zurich, May 2019. https:/www.imf.org/en/News/Articles/2019/05/13/sp051419 -stablecoins-central-bank-digital-currencies-and-cross -border-payments

Andolfatto, David. 2018. "Assessing the Impact of Central Bank Digital Currency on Private Banks," Federal Reserve Bank of St. Louis Working Paper 2018-026C.

Auer, Raphael. 2019. "Beyond the Doomsday Economics of 'proof-of-work' in Cryptocurrencies," BIS Working Paper no. 765, January.

Bech, Morten L., and Rodney Garratt. 2017. "Central bank cryptocurrencies,” BIS Quarterly Review, September.

Calomiris, Charles, and Charles Kahn. 1991. "The Role of Demandable Debt in Structuring Optimal Banking Arrangements," American Economic Review, 81, issue 3, p. 497-513.

Cuthell, Katrina. 2019. "Many Consumers Trust Technology Companies More than Banks," Bain and Company, January. https://www.bain.com/insights/many-consumers-trust -technology-companies-more-than-banks-snap-chart/

Diamond, Douglas and Raghuram Rajan. 2001. "Liquidity Risk, Liquidity Creation, and Financial Fragility: A Theory of Banking," Journal of Political Economy 109(2): 287-327.

Drechsler, Itamar, Alexi Savov, and Philipp Schnabl. 2018. "Banking on Deposits: Maturity Transformation without Interest Rate Risk,” NBER Working Papers 24582, National Bureau of Economic Research, Inc.

Duffie, Darrell. 2019. "Digital Currencies and Fast Payment Systems," mimeo, Stanford University.

Edwards, Sebastian, and I. Igal Magendzo. 2001. "Dollarization, Inflation and Growth,” NBER Working Papers 8671, National Bureau of Economic Research, Inc.

Greenwood, Robin, Samuel G. Hanson, and Jeremy C. Stein. 2016. "The Federal Reserve's Balance Sheet as a
Financial-Stability Tool," 2016 Economic Policy Symposium Proceedings. Jackson Hole: Federal Reserve Bank of Kansas City.

He, Dong, Karl F. Habermeier, Ross B. Leckow, Vikram Haksar, Yasmin Almeida, Mikari Kashima, Nadim Kyriakos-Saad, Hiroko Oura, Tahsin Saadi Sedik, Natalia Stetsenko, Concha Verdugo Yepesn. 2016. "Virtual Currencies and Beyond; Initial Considerations," IMF Staff Discussion Notes 16/3, International Monetary Fund.

Kahn, C., and W. Roberds. 2009. "Why Pay? An Introduction to Payments Economics." Journal of Financial Intermediation 18 (1): 1-23.

Kashyap, Anil, Raghuram Rajan, and Jeremy C. Stein. 2002. "Banks as Liquidity Providers: An Explanation for the Coexistence of Lending and Deposit-Taking," Journal of Finance 57(1): 33-73.

Kocherlakota, Narayana R. 1998. "Money Is Memory," Journal of Economic Theory 81(2): 232-51, August.

Mancini-Griffoli, Tommaso, Maria Soledad Martinez Peria, Itai Agur, Anil Ari, John Kiff, Adina Popescu, and Celine Rochon. 2018. "Casting Light on Central Bank Digital Currency," IMF Staff Discussion Note, November.

Milne, Alistair. 2018. "Argument by False Analogy: The Mistaken Classification of Bitcoin as Token Money," SSRN Electronic Journal. https://ssrn.com/abstract=3290325

Price Waterhouse and Cooper, and Loopring. 2019. "Emergence of Stable Value Coins and a Trust Framework for Fiat-Backed Versions," January. https://loopring.org/resources/pwc -loopring-stablecoin-paper.pdf

Sapienza, Paola, and Luigi Zingales (2012), "A Trust Crisis," International Review of Finance 12(2): 123-31, June.

Tobin, James. 1987. "The Case for Preserving Regulatory Distinctions," Challenge 30(5).

Weber, Warren. 2019. "Stablecoin Protocols," posted online on Medium. https://medium.com/@wew_8484/stablecoin -protocols-9f9e5a9ea71b

\section{CInternational Monetary Fund. Not for Redistribution}




\section{THE RISE OF DIGITAL MONEY}

\section{PART 1}

New Digital Forms of Money

\section{PART 2}

Adoption of E-Money

Could Be Rapid

\section{PART 3}

Effects of E-Money on the

Banking Sector

\section{PART 4}

The Role of Central Banks and Synthetic CBDC

\section{PUBLICATIONS}

The Rise of Digital Money

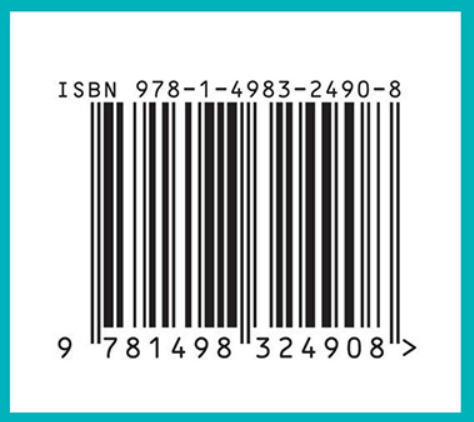

NOTE/19/01 